\title{
Investigating The Association Between Cognitive Ability, Leisure Activity And Emotional Intelligence Among An Ethnically Diverse Student Population From A Medical University In Malaysia
}

\author{
Jaiprakash Mohanraj, Katiravan A/L Kaliannan, Datius Burchard Mutalemwa, Kelly Lim Qian \\ Yu, Manas Kraithad, Nazrarul Uyun Binti Saedun, Vithundran Vinayagam, Wong Yu Yuan
}

\begin{abstract}
The young adult population, often classified as digital natives, have transformed their lifestyle and leisure activity to a large extent when compared to the digitally recluse generation, which suggestively can affect their overall emotional and cognitive development. Our present study, investigated the association between emotional intelligence and cognitive ability among university students engaging in four different types of leisure activity ie. group 1- students engaging in group based physical activities, group 2-students involved in self-engaging physical activity, group 3 were online gamers and group 4 were those with sedentary leisure habits. A total of 100 students were included in this study with 25 in each category. Based on the set criteria's the subjects were classified into the four groups, following which EI-competency based questionnaire was administered. They participants then participated in a validated online gaming tool to tests their cognitive ability. The results showed no significant difference in EI between the four groups however, the group-3 showed better memory and group-4 displayed weak memory when compared to the rest. It was intriguing to observe that all the EI domains affected the spatial planning of their cognitive component. Finally, the Chinese student displayed better cognitive ability when compared to the rest.
\end{abstract}

Keywords: Cognitive ability, Emotional Intelligence, Leisure activity, Young adults, Physical activity, online gaming

\section{INTRODUCTION}

In recent years, there has been a drastic transformation in the lifestyle of different age-groups, including kids, particularly in their late youth and young adulthood. Unlike youngsters a couple of decades back, students today are

Revised Manuscript Received on April 19, 2019.

Dr Jaiprakash Mohanraj, Associate Professor, Department of Biochemistry, MAHSA University, Kuala Lumpur, Malaysia.

Katiravan A/L Kaliannan, MBBS Student, MAHSA University, Kuala

Datius Burchard Mutalemwa, MBBS Student, MAHSA University, Kuala Lumpur, Malaysia.

Kelly Lim Qian Yu, MBBS Student, MAHSA University, Kuala Lumpur, Malaysia.

Manas Kraithad, MBBS Student, MAHSA University, Kuala Lumpur, Malaysia.

Nazrarul Uyun Binti Saedun, MBBS Student, MAHSA University, Kuala Lumpur, Malaysia.

Vithundran Vinayagam, MBBS Student, MAHSA University, Kuala Lumpur, Malaysia.

Wong Yu Yuan, MBBS Student, MAHSA University, Kuala Lumpur, Malaysia. Lumpur, Malaysia.

driving progressively towards inactive ways of life that include time spent on PCs, mobile devices and sitting in front of the TV. This lifestyle leads them to neglect the physical activity that has been typical to this developmental period [2, 3]. Gomez-Pinilla (2013) in their work presented a developing volume of evidence that supports the impact of physical activity on vitality and function of the central nervous system (CNS) and promoting resistance against neurological disorders [4]. As indicated by these investigations, exercise has the exceptional ability to upgrade psychological wellness, and current events are being given to utilize this ability to decrease cognitive decay and mental issue.

Physical activity promotes neuronal growth and survival, along with this, it also provides a source of enjoyment, fulfillment and social interactions. [4, 5] It is plausible to conjecture that physical activity may have protective impact on cognitive ability. It has been further demonstrated that participating in sports is a defensive factor against physical illness and pathological behaviour [6,7]. Game gives a balance between group demands and individual demands, between aggressive behaviour and self-control. It encourages a feeling of having a place with a gathering, and shows adapting to both triumph and annihilation.[8] The World Health Organization and Fonds Gesundes, in fact, have formulated strategies indicating that young adults should dedicate at least $60 \mathrm{~min}$ a day to physical activity (such as going to school on foot, walking up-stairs, and cycling).

Mechanisms for establishing the effect of exercise on elements of mental health and well-being are explained based on their biochemical, physiological, and psycho-social changes [9]. Identifying the biochemical mechanisms involved certainly relies on the identification of raise endogenous opioid peptides in blood during and after exercise, primarily plasma $\beta$-endorphin that are produced with the feeling of euphoria or "runners high" [9]. There has been recent attention paid to the interaction between physical activity and central serotonin (5-hydoxytryptamine [5-HT]) as a mood enhancer [9]. Physiological mechanisms 
are explained by the fact that acute exercise promotes thermogenesis or elevated body core temperature which act as a trigger to increase relaxation and improve mood. Psychosocial mechanisms on the other hand suggests that improvements in perceptions of competence and selfefficacy or confidence of one's body and its capabilities may be increased through regular exercise. Physical activity has played a vital role during biological adaptation and survival of the species through evolution, in a process in which the modern mind was created. In addition, development of brain regions that warrant energy efficiency such as the hypothalamus likely evolved with centers that control cognitive abilities, and this has introduced the concept of the "metabolic brain." Importantly, the areas of the brain most influenced by aerobic fitness are higher order regions involved in control of cognition and memory [4]. In addition, aerobic fitness has been shown to promote better functioning of the brain, especially in neural networks involved in cognitive control of inhibition and attention [10].

Physical activity in the form of games, is a domain where people need to propel themselves to accomplish long haul objectives through hard preparing. Also, competitors are required to reliably adapt to the stress of hard training and competitive pressure, and this incorporates comprehension and controlling their emotions and those of different people (e.g., teammates, opponents, coaches, referees, and spectators) [11]. With regards to leisure-time physical activity, individuals require elevated amounts of motivation to continue participation[12] and most types of physical activity include some level of interpersonal interaction, in which case, behaviour might be governed, at least in part, by emotional intelligence [13, 14].

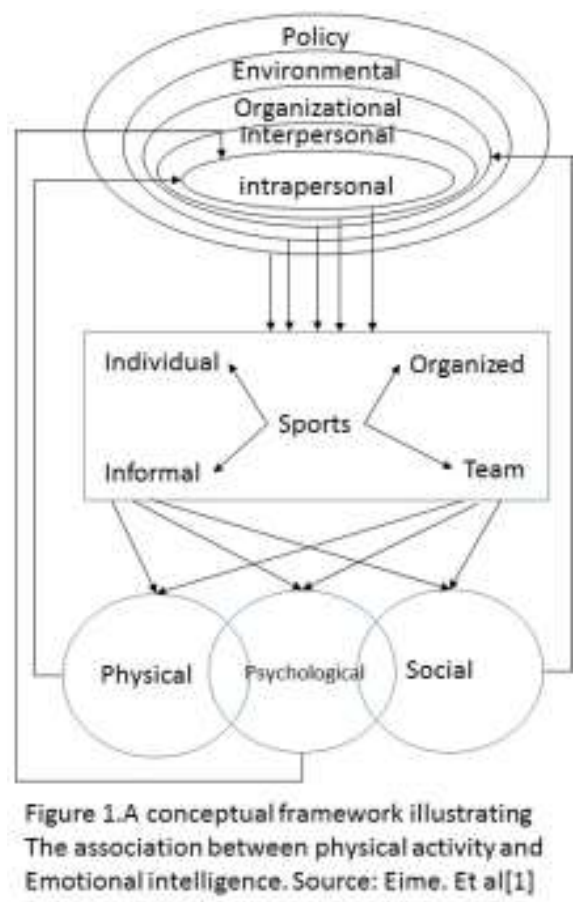

Besides physical activity, some also believe that computer games bring positive impact to the people. Computer games are now one of the most popular and attractive media among adolescents. A study conducted in the USA (2005) on the level of use of computer games by the Americans showed that in the houses of $75 \%$ of the subjects, the device to play computer games was found [15]. The prevalence of adolescents playing computer games was found to be $66.4 \%$ in one of the towns in Isfahan province [16]. Vafaeenajar(2015) indicated that such games are vastly played by adolescents on an average of 2-4 h per day and other studies reported that such games played for 1-5 $\mathrm{h}$ per week or somewhat more than $6 \mathrm{~h}$ in a week[16]. With regard to the impressive effects of computer games on lifestyle, these games have been considered as a revolution, and not just as games to pass leisure time. Researchers found that the positive effects of computer games on them are innovation and imagination skills, eye-hand coordination, and a change in abstract thinking [17].

Many studies investigating the relationship between EI, stress, and health have chosen to highlight on various occupational or educational environments [18]. In a learning environment, higher scores on EQ have been found to predict fewer daily hassles and fewer emotional and physical strain symptoms among Canadian university students tested concurrently [19]. EI refers to individual responses to intrapersonal or interpersonal emotional information and incorporates the identification, expression, understanding and regulation of personal or others' emotions [13, 14]. Emotional tendencies promotes successful sport performance $[20,21]$ and physical activity behaviour [22, 23]. A general agreement exists that emotions are comparatively short-lived in nature [24, 25], but theorists have also suggested that the presence of a more stable, an overarching level that reflects emotional temperaments of the individual [21, 24]. The concept of 'emotional intelligence' (EI) 1 - popularized by Goleman (1995) in the mid-1990s - has been imbibed in many research domains, mostly because of its effectiveness to influence human performance, relationships, and well-being [21]. In conclusion, the investigations found that higher trait EI was identified with more elevated amounts of physical action and positive attitudes toward physical activity. Analysts continue to debate whether EI contributes significantly to emotional, cognitive, and social processes past the notable contribution of IQ and personality traits. The connection between cognitive ability and general intelligence is entrenched, and evidence additionally recommends a connection between cognitive ability and EI [26]. Figure 1 illustrates the conceptual idea of how physical activity is associated with emotional, cognitive, and social processes [1].

Keeferetal(2009) indicates that in spite of the theoretical appeal of the idea that EI may act as a facilitator of these positive life practices, few studies have tested the proposed associations empirically, and fewer still examined the possible mechanisms behind them[18].

There is expanding evidence of association between the absence of physical movement and psychological mental health measures [2]. In spite of this fact, it is clear that physical activity is identified with physical and emotional wellness [27], the connection between physical action and

Published By:

Blue Eyes Intelligence Engineering

\& Sciences Publication 
psychological working requires further study [2]. Cognitive functions include: memory, attention, visual-spatial, and executive functions, while complex cognitive processes include: thinking (abstract, cause and effect, creative thinking, and planning) and language functions [28]. In spite of the significance of this issue, few studies are concerned about the connection amongst sports and cognitive functioning of youngsters in late youth [29], and research to date gives opposing outcomes with respect to the influence of games on cognitive functions in young adults. Some studies demonstrated that physical activity had a beneficial effect on cognitive function [30-32]. Some other studies did not find strong association between physical activity and cognitive function in older adults [33-35].

In the present study, we examined the association between physical activity and cognitive function among the university student with different ethnic and socio-physical activities. We also conducted the study with a view to address the question of whether physical activity (in the form of game \& leisure activity involved) has a predominantly protective effect on cognitive function and to further investigate the effect of emotional intelligence in the study group.

This study proposed three research questions to explore the effect of socio-physical activity on the cognitive ability and emotional intelligence among a university student. The research questions ascertain whether relationships exist among emotional intelligence, social-physical activity in the form of games/leisure activity involved, and cognitive ability using Pearson product-moment correlation coefficient (i.e., Pearson's r).

Research Questions

1.1. Is there a relationship between social-physical activity and leisure Activity?

1.2. Is there a relationship between emotional intelligence and leisure Activity?

1.3. Is there a relationship between the cognitive ability and emotional intelligence scale scores?

\section{MATERIALS AND METHODS}

\subsection{Participants}

The participants were undergraduate students from a university in Kuala Lumpur. They were from a wide range of disciplines including Medicine, Dentistry, Environmental Science, Biomedical Science \& Physiotherapy. Using convenient sampling, 100 participants were inducted into this study out of which $60 \%$ were male and $40 \%$ female. All participants were in their first or second year at the university. Before commencing this project, institutional ethical committee was obtained.

\subsection{Measures} their cognitive ability using an online gaming tool built by Cambridge Brain Sciences who have designed a scientifically-validated, yet easy-to-use cognitive assessment products on an easy to access the online platform [36]. This secure and powerful cognitive assessment platform built for healthcare practitioners is accessible on mobile and tablets, which was used in our study. As per the design of this game,
Cognitive Assessment: The participants were assessed for

the brain cognitive skills and abilities is divided into 4 key areas which further had subsets of games that could be chosen to make the assessment. These areas include 1 . Memory (Spatial span or Monkey ladder or Digit Span or Paired Associates) 2. Reasoning (Double Trouble or Grammatical Reasoning or Object Reasoning or Odd One Out) 3. Concentration (Rotations or Feature Match or Polygons) 4. Planning (Spatial Planning Task or Spatial Search or Spatial Slider).

Emotional Quotient Assessment: The intervention consisted Emotional Intelligence Audit -Competence based, used by Tony-Miller business consultancy in Britain [37, 38]. The questionnaire was designed to address the four classes of Emotional Intelligence 1. Self-Awareness, 2. SelfManagement, 3. Social Awareness, 4. Social Skills. Participants completed the assessment during the first visit and were given a report and one-to-one feedback of their results.

Leisure Activity Assessment: A checklist was designed to assess the type of physical activity and social engagement the participants were involved in their leisure. The checked list enabled us to categorize the activity under four groups Group 1: Interactive sports, this included leisure activities that was done participating in a group which included group sports such as football, badminton etc. Group 2: Noninteractive sports, this includes all those leisure activity that is engaged by an individual on his/her own with interacting in a social group such as those who prefer visiting gym, cycling, jogging Group 3: Online or virtual gamers, include those students who in their leisure activity were restricted to sedentary style and had only virtual interactions over the internet Group 4: Not engaged in any of the above activity were those participant who did not belong to neither of the above group. As an inclusion criteria. This questionnaire was validated using a pilot study conducted prior to its implementation.

\subsection{Procedure}

Participants in this study were briefed on the objectives and benefits of this study following which a written consent was obtained. All volunteers were requested to fill the data sheet which included their personal profile and leading question screen the participant based on the inclusion and exclusion criteria's. Following the selection of the participants the checklist was provided and volunteers guided them on the content and process to complete them. Upon completion of the checklist, they were provided tablets (iPad \& Android Devices) on which the game to assess the cognitive ability were purchased. The participants were expected to complete all the four tasks pre-selected by the research team. In order to test the cognitive skills of participants from different groups, were allowed to take a cognitive function test using only one test from each category. One has to visit the site, http://www.cambridgebrainsciences.com/ and click on the specified tests. Results are obtained were tabulated based on different groupings. Under the Memory category, the test 
"Monkey Ladder" was chosen, for the reasoning category, the test "Grammatical Reasoning was chosen, for the concentration category, the "rotation" test was used and for the planning category, the "Spatial Slider" test was used. The participant were finally requested to complete the Emotional Intelligence Audit - Competence based, used by Tony-Miller business consultancy.

All the data were then transferred to the Statistical software for analysis.

\subsection{Statistical Analysis}

Descriptive statistics were performed to understand and describe the data. Univariate analyses were used to explore the correlation between potential confounding factors, physical activity, and cognitive function. The correlation between cognitive performance and potential confounding factors was examined using Pearson's correlation coefficient for parametric variables (age, gender, EQ score, and physical activity groups).

Those factors found to be significantly correlated with cognitive function were entered as covariates. The correlation between cognitive performance, EQ and physical activity was examined using Pearson's correlation coefficient.

The Statistical Package for the Social Sciences (SPSS) software, version 17.0, was used to conduct the analyses. The level of statistical significance was set at $p<0.05$.

\section{RESULTS}

\subsection{Baseline characteristics}

The mean age of the 100 participants was 21.33 years $(\mathrm{SD}=1.5$, range $=17-25)$, out of which $40 \%$ were female, and $60 \%$ male. The study population's ethnic percentage among Malay, Chinese, Indian \& others were 16\%, 34\%, $16 \% \& 34 \%$ respectively. Twenty five participants in all the four groups of leisure activity (group sports, individual sports such as body building, on-line game and entertainment \& limited socio-physical activity) were selected based on the inclusion and exclusion criteria's.

Table 1 presents the mean and standard deviation of the parameters testing the cognitive ability and emotional intelligence.

\begin{tabular}{lcc} 
& Table 1 & \\
Coguitive Ability & Mean & St. Deviation \\
Menory & 39.97 & 31.5 \\
Reasoning & 24.15 & 22.1 \\
\hline Concentration & 30.65 & 29.7 \\
Planning & 4241 & 28.4 \\
\hline Emotional Intelligence & & \\
Self-Awareness & 34.68 & 5.5 \\
Self-Management & 34.82 & 5.2 \\
\hline Social.Awareness & 34.80 & 4.7 \\
\hline Sociat Skills & 36.4 & 5.4
\end{tabular}

Table 2 presents the comparison between the means of the cognitive scores in various domains; it was observed that there was no significant difference in the scores between male and female. However, a Tukey test done using ANOVA to compare the mean value of the cognitive scores with different ethnic group showed, a significant, difference between Chinese students who displayed better memory and concentration when compared to the others. Whereas, when the scores obtained using EI test were compared between gender and ethnic groups there was no significant difference in there mean value both between and among groups.

\begin{tabular}{|c|c|c|c|c|c|c|c|}
\hline & \multicolumn{7}{|c|}{ ANOVA (Comparing the Means of the Cognitive Ability amongst different subsets) } \\
\hline \multirow{6}{*}{ 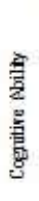 } & & \multicolumn{2}{|c|}{ Gender } & \multicolumn{2}{|c|}{ Ethnicity } & \multicolumn{2}{|c|}{ Leisure Activities } \\
\hline & & F & Sig. & $\mathbf{F}$ & Sig. & F & Sig. \\
\hline & Memory & 2.259 & 0.136 & 8.169 & $.000^{*}$ & 4.024 & $.010^{* 4 *}$ \\
\hline & Reasoning & 2.676 & 0.105 & 1.833 & 0.146 & 0.597 & 0.618 \\
\hline & Concentration & 0.871 & 0.353 & 4.463 & $.006^{4 *}$ & 1.681 & 0.176 \\
\hline & Planning & 0.861 & 0.356 & 1.857 & 0.142 & 1.756 & 0.161 \\
\hline \multirow{5}{*}{ 日 } & & F & Sig. & F & Sig. & F & Sig. \\
\hline & Self-Awareness & 1.126 & 0.291 & 1.011 & 0.391 & 1.4 & 0.247 \\
\hline & Self-Management & 0.389 & 0.534 & 0.388 & 0.762 & 0.827 & 0.482 \\
\hline & Social Aw areness & 5.762 & 0.018 & 0.84 & 0.475 & 0.394 & 0.757 \\
\hline & Social Skilk & 0.008 & 0.929 & 0.609 & 0.611 & 1.699 & 0.172 \\
\hline
\end{tabular}

*Chinese performed significantly better than all the other ethnic population in this category.

**Chinese performed significantly better than Indian \& other ethnic population in this category.

*** Online Gaming group have performed better than all the other categories, but significantly better when compared to sedentary group

On further analysis, it was revealed that the cognitive ability between both the gender group were largely similar however, in the social awareness component on the EI score females were found to be significantly better $(p<0.05)$ than male(Table 2).

Person correlation test was performed to evaluate the cognitive ability and EI among the four subsets of ethnic population. The results showed no significant difference in the EI component of among the students from different ethnic background. However, the Chinese students were observed to have significantly positive correlation in the cognitive skills when compared to the rest (Table 3). A Tukey test conduct using ANOVA also indicated a significant difference in the mean scores of all the four subcategories of cognition that was tested, between Chinese students and the rest.

Table 3: Correlation Between Cognitive A bility with different ethnic subgroups

\begin{tabular}{lll|ccc}
\hline \multirow{4}{*}{ Memory } & & Malay & Chinese & Indian & Others \\
& Pearson Correlation & $-227^{*}$ & $.441^{* *}$ & -0.107 & -0.182 \\
& Sig. (2-tailed) & 0.023 & 0.000 & 0.288 & 0.07 \\
Reasoning & Pearson Correlation & 0.029 & $.209^{*}$ & -0.121 & -0.137 \\
& Sig. (2-tailed) & 0.778 & 0.037 & 0.23 & 0.174 \\
\cline { 2 - 6 } Concentration & Pearson Correlation & 0.008 & $328^{* *}$ & -0.171 & $-202^{*}$ \\
& Sig. (2-tailed) & 0.937 & 0.001 & 0.09 & 0.044 \\
Planning & Pearson Correlation & 0.000 & $.221^{*}$ & -0.115 & -0.133 \\
& Sig. (2-tailed) & 0.996 & 0.027 & 0.256 & 0.189
\end{tabular}

Correlation is significant at the 0.01 level (2-tailed).** Correlation is significant at the 0.05 level (2-tailed).*

In the whole sample, cognitive decline was observed among students with better spatial planning activity, a significantly negative correlation was also observed among students who reported good self-awareness and social skills (Table 4). 
Table 4

Correlatimn Betwete EQ \& Cagnitive Abality

\begin{tabular}{|c|c|c|c|c|c|}
\hline & & Memary & Reasuning & Concentrativa & Plsunirg \\
\hline \multirow[t]{2}{*}{ Self-Amaresens } & Pearsca Comelativa & -130 & .004 & -096 & $-267^{\prime \prime}$ \\
\hline & Sig $(2-$-aled & .199 & 971 & 343 & .607 \\
\hline \multirow[t]{2}{*}{ Sell-Msaragement } & Pearsca Comelstiva & -1072 & .007 & .013 & -.074 \\
\hline & Sig (2-taled) & 478 & $94^{7}$ & 399 & 462 \\
\hline \multirow[t]{2}{*}{ Sycial Anareaess } & Pearica Comelativa & nas & .040 & -140 & $-229^{*}$ \\
\hline & Sig $(2$-tailed $)$ & 782 & 619 & 692 & $\omega 2$ \\
\hline \multirow[t]{2}{*}{ Social Skills } & Pearssa Comelativa & 1802 & -012 & -.087 & $-256^{\circ}$ \\
\hline & Sis (2-maled) & .117 & 905 & 359 & .10 \\
\hline
\end{tabular}

Correlation is significant at the 0.01 level (2-tailed).** Correlation is significant at the 0.05 level (2-tailed).*

Table 5 shows the correlation matrix that was obtained for the 4 test groups tested for their cognitive abilities and EI. There was significant negative correlation $(\mathrm{p}<0.05)$ in the memory component and those who had engaged in limited and students in this group significantly negative correlation with $(\mathrm{p}<0.05)$ their social skills. On the contrary, the students who are online gamers, were found to have significant positive correlation with the memory component of their cognitive ability.

\begin{tabular}{|c|c|c|c|c|c|c|}
\hline \multicolumn{7}{|c|}{ Correiation Hetween Cognitive Ability \& EI with Letware Activity } \\
\hline & & & $\begin{array}{l}\text { Groupl } \\
\text { Sporta }\end{array}$ & $\begin{array}{c}\text { Group2 } \\
\text { Gym }\end{array}$ & $\begin{array}{l}\text { Group3 } \\
\text { Online } \\
\text { Granes }\end{array}$ & $\begin{array}{l}\text { Group4 } \\
\text { Limited } \\
\text { Plysucal } \\
\text { Activity }\end{array}$ \\
\hline \multirow{8}{*}{$\begin{array}{l}\frac{b}{E} \\
\frac{c}{c} \\
\text { है } \\
\text { है } \\
\text { ह }\end{array}$} & \multirow{2}{*}{ Memory } & $\begin{array}{l}\text { Pearact } \\
\text { Comrintion }\end{array}$ & -0.025 & -2062 & $.309^{\prime \prime}$ & $-222^{\circ}$ \\
\hline & & Sin $\{2$ triled $\}$ & 0.507 & 0.53 ? & 0.002 & 0.027 \\
\hline & \multirow[t]{2}{*}{ Ressaning } & $\begin{array}{l}\text { Peanton } \\
\text { Cosrelation }\end{array}$ & -0.004 & $-0,079$ & 0.127 & .0045 \\
\hline & & Sig. (2-tailed) & 0.972 & 8.436 & 0207 & 9.656 \\
\hline & \multirow[t]{2}{*}{ Concentrabian } & $\begin{array}{l}\text { Pesarson } \\
\text { Comrelmion }\end{array}$ & 4.051 & 0.167 & 0.188 & 0.03 \\
\hline & & Sig. (2-taibed) & 0.517 & 0.097 & 0.061 & Q.77 \\
\hline & \multirow[t]{2}{*}{ Planaing } & $\begin{array}{l}\text { Pearicti } \\
\text { Correlation }\end{array}$ & -0.053 & 0.176 & 0.183 & 0.046 \\
\hline & & Sig (2 tailed) & 0,602 & 0.08 & 0.069 & 0.65 \\
\hline \multirow{6}{*}{ 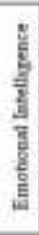 } & \multirow{2}{*}{$\begin{array}{l}\text { Sell. } \\
\text { Awaremeas }\end{array}$} & $\begin{array}{l}\text { Pearnon } \\
\text { Corretation }\end{array}$ & 0.071 & 0.155 & -0.058 & -0.138 \\
\hline & & Sin (2.tailed) & 0.452 & 0.124 & 0.384 & 0.17 \\
\hline & \multirow{2}{*}{$\begin{array}{l}\text { Self- } \\
\text { Management }\end{array}$} & $\begin{array}{l}\text { Pearsed } \\
\text { Correlatios }\end{array}$ & 0.079 & 0.015 & 0.121 & 0.134 \\
\hline & & Sig. (2-tailed) & anz & 0.879 & 0.231 & 0.184 \\
\hline & \multirow{2}{*}{\begin{tabular}{|l} 
Social \\
Awartaess
\end{tabular}} & $\begin{array}{l}\text { Puarzen } \\
\text { Comrelation }\end{array}$ & -0.025 & 0.104 & -0.01 & .0669 \\
\hline & & Sig. (2-tuiled) & 0.002 & 2305 & 0.922 & 8494 \\
\hline
\end{tabular}

Correlation is significant at the 0.01 level (2-tailed).** Correlation is significant at the 0.05 level (2-tailed).*

\section{DISCUSSION}

The purpose of this study was to shed light on the relationships that exist among leisure participation, cognitive ability, and emotional intelligence, and show how these three parameters impacts students studying in a university in Malaysia. Accordingly, the study examined the relationship among leisure participation involvement (Group activity, Individual sports, online-gaming \& those with limited socio-physical engagement), cognitive ability, and emotional intelligence among the students studying at a university in Malaysia. It was the intention of the study to realize research findings that would inform university administrators within the jurisdiction of its application with information on the need to institute changes in the environments that positively accord leisure activities and emotional intelligence to foster positive cognitive development with the students in the university.

During the entire period of data collection, the research team assured the participants' confidentiality by assuming coded names for research questionnaires. This precaution ensured that instead of having the names of the respondents appear on their individual questionnaires, the coded name of the research team member administering it appeared. As such, privacy and confidentially of the study participants were assured. Demographic characteristics of the respondents were also examined with the intention of being able to examine whether the demographic factors that characterized the study respondents influenced the findings of the research study in any way. The demographic information that was collected from the respondents included gender, age and ethnicity.

In terms of instrumentation, assessment of cognitive ability utilized an online gaming tool to determine the participation level in four categories; memory, reasoning, concentration and planning. The Emotional Intelligence Audit -Competence based, used by Tony-Miller business consultancy evaluated participants' on self-awareness, selfmanagement, social awareness and social skills.

The research findings indicated that a majority of the participants that took part in this study were between the age group 17 to 25 years old. The implication, then, is that the participants in this study were relatively young, more of young adults. From such a perspective, this may explain the leisure activity involvement of these respondents. For example, an increasingly higher number of participants reported that they preferred online entertainment when compared to the more physically engaging sporting activity. The gender distribution in our study group was $40 \%$ \& $60 \%$ for female and male population, respectively which was the proportion reflected in the Malaysian Demographic Profile 2018 for the age group between 15-24 years[39].

The comparison of mean cognitive scores among the different ethnic group revealed an interesting pattern of results suggesting that ethnicity showed a strong association with memory and concentration when compared with the other cognitive domains. A correlation statistics further indicated a significantly positive correlation between Chinese students demonstrating better cognitive ability in all the four domains. These results are consistent with observations reported by various authors.[40, 41] It was also noted that gender did not affect the scores assessing cognitive ability and emotional intelligence in this study population.

Comparing the means scores of cognitive ability and emotional intelligence with leisure activity, it was observed that leisure activity significantly affected the memory domain whereas all the other components were more or less similar for this study population. This indicates that reasoning, concentration and planning domains were largely similar irrespective of the leisure activity adopted by the study population contradicting the finding proposed by Bidzan-Bluma(2018) [2] and others[42, 43]. This could be due to the reason that most of the research were done in children or elderly and very little evidence exists on the impact on the young adult population.

The whole study population demonstrated that the 
planning domain had a negative association with all the four domains of emotional intelligence. This indicates that as the emotional quotient increases the spatial planning of cognitive domain decreases. Reitter, D.(2010) suggested that decline in the spatial planning is found to be related to environmental factors that is tied to memory access and perceptual judgments[44, 45]. It was also noted that spatial planning was strongly associated with self-awareness than social awareness indicating that more social interaction enabling the students to interact with their environment which eventual built their spatial planning domain.

Finally, the core research question was tested comparing the four groups based on leisure activity with their cognitive ability and emotional quotient. Interesting it was observed that there was a significantly strong positive correlation between online gamers and memory. Over the years games became more complex, often social environments, sometimes involving large distributed communities. Prensky (2006) suggest that in many ways, games have become complex learning systems suggested potential of games with regard to improving computer self-efficacy is an encouraging finding and should be more fully exploited[46] [47]. We thus suggest that online gaming which demonstrated better memory when compared to those engaging in sports or other leisure activity can be used in the learning process to enhance the students' academic performance. Educational games should cautiously navigate the problem of being sufficiently fascinating and to draw in understudies, without being addictive and along these lines inconvenient to scholarly execution[47, 48]. However, study done by Bidzan-Bluma(2018) contradicts this finding[2].

Interestingly participants of group 4, were found to have a significantly negative correlation (Pearson correlation value of -0.222) with the memory component of the cognitive domain indicating those engaging in limited sociophysical leisure activity had poor memory when compared to others. We found that productive activity appeared to show the positively association with better cognitive ability, while physical activity was not significantly associated with cognitive decline when participation in social and productive activities were taken into account. $\mathrm{Su}$ (2015) in their work showed similar findings concurring to the current study[49].

This study needs to be expanded in a larger population to reaffirm the finding, and also factors like diet, social structure, and measurement of IQ could provide a more corroborative evidence in understanding the cognitive function of this study population.

Exercise needs to be promoted regardless of its impact on mental fitness as it consists of significant reduction in risks for a variety of illnesses and problems among all sectors in the society. The body of literature summarized in this article additionally supports the want for workout promoting in the typical public as it ought to prove to be a cheap and handy vehicle for improving self-perceptions, mood, lifestyles satisfaction, social interaction and first-class of life. Further, inclusion of educational games into the teaching and learning activity must be considered, with caution towards its side-effects facilitating the student's overall cognitive development.

\section{CONCLUSIONS}

Engagement in various types' leisure activities can have a significant effect on the cognitive development and emotional intelligence of an individual, especially in the young adult age group. Most of the literature show that the physical engaging leisure activities promote better cognitive and emotional development. However, in our study we find that physical activate participant have displayed a similar cognitive ability and EI when compared to the others. We have also found the gamer appear to have better memory than the rest of the study population. It was interning to observe that all the domains of measure EI influenced the spatial planning cognitive component. Although the emotional intelligence was found to be similar among the four race, the Chinese student appear to have better cognitive ability than the rest. It is evident that physical activities, positively influence the cognitive ability and emotional behaviour, however the effect of games has also shown positive affect on cognition.

\section{AUTHOR CONTRIBUTIONS}

$\mathrm{JM}, \mathrm{KK}, \mathrm{DBM}, \mathrm{KL} \& \mathrm{MK}$ were involved in the study design and data analysis. KK, DBM, KL, MK, NU, VV \& WYY collected data. JM, KK, DBM, KL, MK, NU, VV \& WYY were active in manuscript preparation and analysis. All the authors read the final draft and approved.

\section{FUNDING}

"This research received no external funding"

\section{CONFLICTS OF INTEREST:}

Declare conflicts of interest or state "The authors declare no conflict of interest.

\section{REFERENCES}

1. Eime, R.M., et al., A systematic review of the psychological and social benefits of participation in sport for children and adolescents: informing development of a conceptual model of health through sport. International journal of behavioral nutrition and physical activity, 2013. 10(1): p. 98

2. Bidzan-Bluma, I. and M. Lipowska, Physical activity and cognitive functioning of children: a systematic review. International journal of environmental research and public health, 2018. 15(4): p. 800 .

3. Graf, C., Aktiv in jedem Alter-Sport und Ernährung in den verschiedenen Lebensphasen: Kinder. Aktuelle Ernährungsmedizin, 2016. 41(S 01): p. S32-S34.

4. Gomez-Pinilla, F. and C. Hillman, The influence of exercise on cognitive abilities. Comprehensive Physiology, 2013. 3(1): p. 403-428.

5. Teychenne, M., K. Ball, and J. Salmon, Associations between physical activity and depressive symptoms in women. International journal of behavioral nutrition and physical activity, 2008. 5(1): p. 27.

6. Bobrowski, K., Czas wolny a zachowania ryzykowne młodzieży. Alkoholizm i Narkomania, 2007. 20(3): p. 267-287.

7. Ostaszewski, K., A. Rustecka-Krawczyk, and M. Wójcik, 
Czynniki chroniące i czynniki ryzyka związane $z$ zachowaniami problemowymi warszawskich gimnazjalistów: raport dla szkół i władz oświatowych Warszawy z realizacji pierwszego etapu badań pn" Rola czynników ryzyka i czynników chroniących w rozwoju zachowań problemowych u młodzieży szkolnej: badania warszawskich gimnazjalistów". 2008: Instytut Psychiatrii i Neurologii.

8. Spence, D., A sporting chance. Bmj, 2006. 332(7542): p. 675.

9. Fox, K.R., The influence of physical activity on mental well-being. Public health nutrition, 1999. 2(3a): p. 411418.

10. Colcombe, S.J., et al., Cardiovascular fitness, cortical plasticity, and aging. Proceedings of the National Academy of Sciences, 2004. 101(9): p. 3316-3321.

11. Laborde, S., F. Dosseville, and M. S. Allen, Emotional intelligence in sport and exercise: A systematic review. Vol. 26. 2015

12. Kodama, S., et al., Association between physical activity and risk of all-cause mortality and cardiovascular disease in patients with diabetes: a meta-analysis. Diabetes care, 2013. 36(2): p. 471-479.

13. Mayer, J.D. and P. Salovey, What is emotional intelligence. Emotional development and emotional intelligence: Educational implications, 1997. 3: p. 31.

14. Petrides, K.V. and A. Furnham, Trait emotional intelligence: Behavioural validation in two studies of emotion recognition and reactivity to mood induction. European journal of personality, 2003. 17(1): p. 39-57.

15. Sherry JL, L.K., Greenberg BS, Lachlan K., Video game uses and gratifications as predictors of use and game preference. Playing video games: Motives, responses, and consequences. International Journal of Sports Marketing and Sponsorship, 2006. 28:24(1): p. 213-24.

16. Vafaeenajar A, M.M., Moshki M, Ebrahimipour H, Tehrani H, Esmaily H., Determining the Theory of Planned Behavior's Predictive Power on Adolescents' Dependence on Computer Games. Iranian Journal of Health Education and Health Promotion., 2015. 15;2(2): p. 303-11.

17. Mohammadi M, R.A., Mehrabi T, Rezaei Dehaghani A., Association between playing computer games and mental and social health among male adolescents in Iran in 2014. Iranian journal of nursing and midwifery research, 2016. 2(21): p. 153.

18. Keefer, K., J. Parker, and D. H. Saklofske, Emotional Intelligence and Physical Health. 2008. 191-218.

19. Dawda, D. and S.D. Hart, Assessing emotional intelligence: Reliability and validity of the Bar-On Emotional Quotient Inventory (EQ-i) in university students. Personality and individual differences, 2000. 28(4): p. 797-812

20. Jones, M.V., Emotion regulation and performance. The Oxford handbook of sport and performance psychology, 2012: p. 154-172.

21. Laborde, S., M. Raab, and F. Dosseville, Emotions and performance: Valuable insights from the sports domain. Handbook of psychology of emotions: Recent theoretical perspectives and novel empirical findings, 2013. 1: p. 325-358.

22. Mohiyeddini, C., R. Pauli, and S. Bauer, The role of emotion in bridging the intention-behaviour gap: The case of sports participation. Psychology of Sport and Exercise, 2009. 10(2): p. 226-234

23. Wang, X., The role of anticipated negative emotions and past behavior in individuals' physical activity intentions and behaviors. Psychology of Sport and Exercise, 2011. 12(3): p. 300-305.
24. Lazarus, R.S., How emotions influence performance in competitive sports. The sport psychologist, 2000. 14(3): p. 229-252.

25. Scherer, K.R., What are emotions? And how can they be measured? Social science information, 2005. 44(4): p 695-729.

26. Fernández-Berrocal, P. and P. Checa, Editorial: Emotional Intelligence and Cognitive Abilities. Frontiers in Psychology, 2016. 7(955).

27. Fedewa, A., C. Cornelius, and S. Ahn, The use of bicycle workstations to increase physical activity in secondary classrooms. Health Psychology Report, 2018. 3(1).

28. Evans, J.J., Basic concepts and principles of neuropsychological assessment. Handbook of clinical neuropsychology, 2003: p. 15-26.

29. Ellemberg, D. and M. St-Louis-Deschênes, The effect of acute physical exercise on cognitive function during development. Psychology of Sport and Exercise, 2010. 11(2): p. 122-126.

30. Lindsay, J., et al., Risk factors for Alzheimer's disease: a prospective analysis from the Canadian Study of Health and Aging. American journal of epidemiology, 2002. 156(5): p. 445-453.

31. Podewils, L.J., et al., Physical activity, APOE genotype, and dementia risk: findings from the Cardiovascular Health Cognition Study. American journal of epidemiology, 2005. 161(7): p. 639-651.

32. Ku, P.-W., C. Stevinson, and L.-J. Chen, Prospective associations between leisure-time physical activity and cognitive performance among older adults across an 11year period. Journal of Epidemiology, 2012. 22(3): p. 230-237.

33. Sturman, M.T., et al., Physical activity, cognitive activity, and cognitive decline in a biracial community population. Archives of Neurology, 2005. 62(11): p. 1750-1754.

34. Leung, G.T., et al., Examining the association between participation in late-life leisure activities and cognitive function in community-dwelling elderly Chinese in Hong Kong. International psychogeriatrics, 2010. 22(1): p. 213.

35. Iwasa, H., et al., Leisure activities and cognitive function in elderly community-dwelling individuals in Japan: a 5year prospective cohort study. Journal of psychosomatic research, 2012. 72(2): p. 159-164.

36. Science, C.B., CBS Research - Cognitive test battery. 2017.

37. Consultants, T.M.B., Emotional Intelligence Competency Based Questionaire. 2017.

38. Hindle, D. and T. Miller, Developing skills in working individually with children. Journal of Social Work Practice, 1997. 11(1): p. 9-15.

39. Malaysian Demographi Profile. 2018 https://www.indexmundi.com/malaysia/demographics_pr ofile.html

40. Albaity, M., M. Rahman, and I. Shahidul, Cognitive reflection test and behavioral biases in Malaysia. Judgment and Decision Making, 2014. 9(2): p. 148.

41. Oechssler, J., A. Roider, and P.W. Schmitz, Cognitive abilities and behavioral biases. Journal of Economic Behavior \& Organization, 2009. 72(1): p. 147-152.

42. Biddle, S.J., T. Gorely, and D.J. Stensel, Healthenhancing physical activity and sedentary behaviour in children and adolescents. Journal of sports sciences, 2004. 22(8): p. 679-701.

43. van der Fels, I.M., et al., The relationship between motor skills and cognitive skills in 4-16 year old typically 
developing children: A systematic review. Journal of Science and Medicine in Sport, 2015. 18(6): p. 697-703.

44. Reitter, D. and C. Lebiere, A cognitive model of spatial path-planning. Computational and Mathematical Organization Theory, 2010. 16(3): p. 220-245.

45. Lin, L. and M.A. Goodrich, A Bayesian approach to modeling lost person behaviors based on terrain features in wilderness search and rescue. Computational and Mathematical Organization Theory, 2010. 16(3): p. 300323.

46. Prensky, M., In Presentation at the 2006 educause learning initiative (eli) annual meeting, January 30, 2006. San Diego, California, 2006.

47. Paraskeva, F., S. Mysirlaki, and A. Papagianni, Multiplayer online games as educational tools: Facing new challenges in learning. Computers \& Education, 2010. 54(2): p. 498-505.

48. Papert, S., Mindstorms: Children, computers, and powerful ideas. 1980: Basic Books, Inc.

49. Su, E.X., et al., Physical activity and cognitive function of community Chinese elderly in Hong Kong (HK) and Guangzhou (GZ). International psychogeriatrics, 2015. 27(6): p. 959-966

\section{AUTHORS PROFILE}

Dr Jaiprakash Mohanraj, Associate Professor, Department Of Biochemistry, Faculty Of Medicine, MAHSA University. Currently pursuing $\mathrm{PhD}$ in Medical Science, University Malay (Sabah), Malaysia. He has completed PG Certificate In Medical Education, University of Dundee, Dundee, MD in Clinical Biochemistry, Rajiv Gandhi University Of Health Sciences, India \& MBBS from Bangalore University, India. His research interest is in Clinical Biochemistry, Oxidative Stress, Leptin, Leptin Receptors, Quantum Biology, Professionalism, Formative Assessment, Learning Styles, Blended Learning, Spiritual Medicine, Systematic Review \& Meta-Analysis. 